\title{
Clinical Observations Evaluator
}

National Cancer Institute

\section{Source}

National Cancer Institute. Clinical Observations Evaluator. NCI Thesaurus. Code C119801.

A person who determines the significance of a clinical observation assessment. 